\title{
Numerical analysis of stresses for cured-in-place-pipe linings
}

\author{
C. Chuk ${ }^{1}$, G. Urgessa ${ }^{1} \&$ H. Thippeswamy ${ }^{2}$ \\ ${ }^{1}$ Department of Civil, Environmental and Infrastructure Engineering, \\ George Mason University, USA \\ ${ }^{2}$ Infrastructure and Environmental Engineering, \\ Fairfax County Public Schools, USA
}

\begin{abstract}
Underground pipes, such as water supply pipes and sewer pipes, are subjected to reduced strength and cracking due to aging. In order to combat strength reductions, excavation technologies have been used widely that allow replacing existing pipes with new pipes. However, these methods require road closures, traffic regulation and repaving. Various non-excavation (trenchless) repairs have been used in the last twenty years. This paper presents numerical analysis methods of stresses for pipes rehabilitated with cured-in-place-pipe (CIPP) linings. A CIPP lining is the common name given to the installation of a resin impregnated tube into a deteriorated pipe and curing it in place to produce a new structural pipe within a pipe. Examples of different liner types and their effect on reducing pipe wall stresses are presented.
\end{abstract}

Keywords: CIPP, FRP, pipe rehabilitation, pipe lining, pipe stresses.

\section{Introduction}

The need to rehabilitate, replace, and repair drinking water and wastewater systems in the United States is growing. The United States water infrastructure (water distribution lines, sewer lines, water treatment plants, and storage facilities) protects the environment as well as the public health. Most of the drinking and wastewater infrastructure was built 30 years after the end of World War II. It is very important for the country to prepare for the infrastructure rehabilitation and replacement over the next few decades. If these problems are ignored, the nation's water and public health are put at risk. Selvakumar et al. [1] 
presented the predicted cost for water supply distribution system rehabilitation at $\$ 138$ billion over a twenty year period. $\$ 77$ billion will be needed to rehabilitate pipelines while the rest is needed for maintaining and replacing existing drinking water systems. The authors also present representative costs for utility managers to estimate the budget needed for the rehabilitation and replacement of the water pipelines.

An aged system does not necessarily mean that it has problems nor it requires replacement if it was properly maintained. A well maintained water infrastructure can operate over a long period of time. The Environmental Protection Agency (EPA) survey [2] found that in systems that serve more than 100,000 people, about $30 \%$ of the pipes were between 40 and 80 years old and about $10 \%$ of the pipes were more than 80 years old. In terms of the useful life of the water infrastructure, water treatment plants usually have a life of 20-50 years before they require expansion or rehabilitation. Depending on the material and the environment, pipes can have a life of 20 to over 100 years. The material choice of the pipes is a bigger contributor to failure than age. Steel pipes that are 80 years or older have been proven to be more resilient than different material pipes installed more recently. It is very important to properly maintain the water infrastructure because the infrastructure itself and the costs due to a failure are expensive. A properly maintained system can operate safely for a many years.

The EPA [2] presented an example of how poor maintenance can affect the water quality and costs. Long-term corrosion in older pipes can have reduced carrying capacity due to tuberculation. In order to make up for the reduction in carrying capacity, an increase in power and pumping is required. By doing so, the operation and maintenance costs also increase. The water-main also weakens due to the reduction in the wall thickness. The reductions in carrying capacity and in strength can increase pumping, breakage, and repair costs, and, consequently, the cost of water delivery. The EPA has also provided information on the water distribution systems in the United States. This clean and safe water provides the people with health, environmental, social, and economic benefits. EPA has estimated that if spending for capital investment and operations and maintenance remain at current levels, the potential gap in funding for 2000-2019 would be approximately $\$ 263$ billion for the drinking water infrastructure. There are 240,000 water main breaks per year in the United States. The number of breaks increases substantially near the end of the system's service life. Large utility breaks in the Midwest increased from 250 per year to 2,200 per year during a 19 year period. In 2003, Baltimore, Maryland, reported 1,190 water main breaks - that is more than three per day.

While for wastewater collection systems, EPA [2] has estimated that if spending for capital investment and operations and maintenance remain at current levels, the potential gap in funding for 2000-2019 would be approximately $\$ 270$ billion for our wastewater infrastructure. There are about 600,000 miles of wastewater sewer pipes in the United States. The wastewater collection systems consist of networks of pipes, pumping stations, and other equipments. These wastewater collection systems provide pollution control by transporting wastewater, storm water, irrigation and wash water, and infiltration 
or inflow. EPA [3] has presented three issues with the wastewater collection systems. The wastewater and storm water collection systems are aging; some are over 100 years old. The change in population requires new infrastructure and maintenance of existing collection systems. The current technologies and management approaches may not be adequate to address the emerging issues.

Sterling et al. [4] presented the annual report card showing the grade for the US wastewater infrastructure, which was a D in 2007. Even though there is replacement and rehabilitation of roughly 8,000 miles of sewer each year costing approximately $\$ 4.8$ billion, the wastewater infrastructure still received the lowest grade in the infrastructure category. The authors also provided tables showing percentage distribution of pipe materials within various sizes of pipes. For gravity sewer systems, pipes with 4 inches to 20 inches diameter are mostly made of vitrified clay pipes (VCP), while pipes with greater than 21 inches in diameter are mostly made of reinforced concrete pipes (RCP). For force main systems, pipes with less than 36 inches diameter are mostly made of ductile iron (DI) and larger pipes are mostly made of prestressed concrete cylinders or concrete cylinders. For water distribution systems, the four main materials used are asbestos cement, unlined cast iron, cement mortar lined cast iron, and cement mortar lined ductile iron. The current pace of replacing water distribution pipes is less than $1 \%$ a year.

\section{Review of rehabilitation techniques}

\subsection{Rehabilitation methods}

There are many methods for rehabilitating water distribution and wastewater systems as well as methods for replacing them. Rehabilitation involves using the old pipe as part of the new system one or it involves supporting a new lining. The methods for lining are separated into two categories, which are nonstructural and structural. Non-structural lining is used to increase the serviceability of the pipe by applying a thin coating of either epoxy or cement mortar inside the pipe to prevent leaks. This thin coating however does not increase structural integrity. On the other hand, structural lining improves the structural integrity of the pipe by placing a watertight structural within the existing pipe. There are four structural lining techniques that include: slip-lining, cured-in-place pipe (CIPP), fold and form pipe, and close-fit pipe [1].

There are two accepted techniques to replace pipelines, which are trenchless and open-trench methods. Trenchless techniques are less costly and do not disrupt surface traffic, business, and other activities while open-trench techniques are more cost intensive and do have problems in developed areas because the pipes may be under streets, sidewalks, buildings, etc. The three common trenchless techniques include pipe bursting, micro-tunnelling, and horizontal directional drilling. 


\subsection{Focus on cured-in-place pipe (CIPP) linings}

CIPP linings have been used since 1971 but improvements have been made continuously over the years [5]. These improvements are driven by the need to stay competitive in the rehabilitating lining industry. Some new innovations used in the United States includes the use of ultraviolet cure liner systems, the increase of steam cure rather than water, and the use of composite liner technologies. CIPP lining involves inserting a tube that is saturated with thermosetting resin into the damaged pipe. The tube is then expanded using either air or water pressure. Lastly, the resin is either cured naturally using steam or hot water, or using ultraviolet light. There are different types of liners that can be used for this purpose. Conventional CIPP uses either a fiberglass reinforced material or needled felt material. The resin used is usually unsaturated polyester, epoxy vinyl, or epoxy with catalysts. There are different types of liners that are suited for different parts of the pipe. The standard CIPP is a straight tube that is used for mainlines. The Top Hat Liner is used for a lateral-to-mainline connection, where the liner forms a top hat shape. T-liner is used for relining both a lateral-to-mainline connection and a lateral. A composite CIPP consists of layers of carbon fiber and/or fiberglass on top of the conventional CIPP. The carbon fiber provides higher stiffness, while the fiberglass provides corrosion resistance. A protective coating is then added on the inside of the liner for increased corrosion resistance as well as surface smoothness. Composite CIPP is usually used for medium to large diameter pipes. The CIPP method creates minimal annulus and does not require grouting. The flow capacity is also not affected after the CIPP liner is installed.

Lee et al. [6] reported that the use of fiber-reinforced polymer (FRP) composite materials is a potential solution to rehabilitating underground pipelines. FRP composites are very good construction materials because of their high specific stiffness, high specific strength, corrosion resistant, tailorability of properties, and enhanced fatigue life. In terms of the performance of FRP, the mechanical properties as well as the thickness and fiber orientation can cause significant deviations. Lee et al. [6] also determined the instantaneous reliability by calculating the failure probability for similar pipes made from glass FRP (GFRP), carbon FRP (CFRP), and steel. The FRP materials used have fiber volume fraction (FVF) of $30 \%$ with all the fibers in the circumferential direction. Based on their results, the material that provides the lowest probability of failure of $0.81 \%$ is the CFRP pipe, followed by the steel pipe with $2.5 \%$, and lastly $4.53 \%$ for the GFRP pipe. Although this instantaneous reliability test does not show long-term performance of the pipes, the CFRP materials have greater asbuilt reliability than an existing steel pipe. There are two main factors that influence the FRP composite quality, which are the FVF and thickness of the liner. In order for a CFRP material to exceed the reliability of an equivalent steel pipe, a FVF of $27 \%$ or higher is needed. While a FVF of $34 \%$ or higher is needed for a GFRP material. FVF is usually in the range of $20 \%$ to $30 \%$ for hand layup and can go up to $60 \%$ with processes such as resin transfer molding (RTM). For 
long-term performance, in order to have a lower probability of failure than a new steel pipe for 50 years, a CFRP material with a FVF of $40 \%$ or greater is need.

Mifek [7] evaluated the chemical resistance of resins used in CIPP application since the resin used is a major design factor. The strength and stiffness of the pipes is determined by the strength of the resin used in the lining process. The paper showed that three generic thermosetting resins, polyester, epoxy, and vinyl ester, all have different short-term flexural and tensile properties. Polyester is commonly used in sewer applications, while epoxy is commonly used in potable water and pressure pipe applications. Vinyl ester is used for heavy duty, industrial and special waste applications. Overall, the epoxy vinylester was more superior to both the epoxy and polyester resins due to the balance stiffness and high strength.

\section{Numerical analysis of stresses for CIPP lining}

The following section presents a limit state stress model to analyze rehabilitated underground pipelines. The section includes discussions for both the circumferential and the longitudinal directions. Numerical examples of circumferential stress determinations are provided at a later section. Circumferential pipeline stresses include internal fluid pressure, external soil $\mathrm{g}$ and traffic loading. Longitudinal stresses include bending stress caused by uneven bedding, operating temperature differences, as well as internal fluid pressure. For underground pipelines, shear stresses are usually unaccounted because the critical stresses are either at the top or at the bottom of the pipe where shear stresses are almost non-existent [8]. One assumption made is that the normal stresses on the inside wall of the pipe caused by both internal and external forces can be algebraically added. This assumption can only be made if the stresses stay within the elastic range of the pipe material.

\subsection{Circumferential stresses}

For pipes with internal fluid pressure, uniform circumferential tension is produced across the wall given the wall thickness is small relative to the radius of the pipe and the fluid density is small compared to the fluid pressure. The uniform circumferential tension due to internal pressure, $\mathrm{S}_{\mathrm{c} \text {-fluid, }}$ is determined by

$$
S_{c-\text { fluid }}=\frac{p r}{t}
$$

where $\mathrm{p}$ denotes internal pressure, $\mathrm{r}$ denotes pipe radius, $\mathrm{t}$ denotes pipe thickness, and $r \gg t$.

External loads cause the pipe to have bending stresses in the circumferential direction in the pipe wall. Circumferential stresses are dependent on transverse spread of the load at the top and bottom of the pipe. The critical values are usually found either on the top or on the bottom of the pipe. The Spangler stress formula [9] is used to estimate the circumferential bending stresses caused by vertical loads (soil and traffic) at the bottom of the pipe cross section. 
The circumferential stress caused by soil, $\mathrm{S}_{\mathrm{c}-\text { soil }}$, is determined by

$$
S_{c-s o i l}=\frac{6 k_{m} W_{\text {soil }} E t r}{E t^{3}+24 k_{d} p r^{3}}
$$

where $\mathrm{k}_{\mathrm{m}}$ is the bending moment coefficient, $\mathrm{W}_{\text {soil }}$ is the load due to soil, $\mathrm{E}$ is the modulus of elasticity of the pipe material, $\mathrm{k}_{\mathrm{d}}$ is the deflection coefficient and the remaining parameters as defined earlier. Both $\mathrm{k}_{\mathrm{m}}$ and $\mathrm{k}_{\mathrm{d}}$ are dependent on the distribution of vertical load and the associated reaction which is associated with the bedding angle given in Table 1.

Table 1: $\quad$ Spangler stress parameters.

\begin{tabular}{|c|c|c|}
\hline Bedding angle (degrees) & Moment coefficient & Deflection coefficient \\
\hline 0 & 0.294 & 0.110 \\
\hline 30 & 0.235 & 0.108 \\
\hline 60 & 0.189 & 0.103 \\
\hline 90 & 0.157 & 0.096 \\
\hline 120 & 0.138 & 0.089 \\
\hline 150 & 0.128 & 0.085 \\
\hline 180 & 0.125 & 0.083 \\
\hline
\end{tabular}

The modulus of elasticity of fiberglass pipes ranges from 500,000 psi to $5,000,000$ psi [10]. Most references recommend the bedding angle to be 30 degrees, which corresponds to an open trench condition. The prism formula given by eqn. (3) can be used to determine the weight of the soil right above the pipe per unit length

$$
W_{\text {soil }}=\gamma H d
$$

where $\gamma$ is unit of weight of soil backfill, $\mathrm{H}$ denotes depth of cover (typically between 2.5 feet to 32 feet), d denotes the pipe diameter and the remaining diameters as defined earlier.

The circumferential stress caused by traffic loads, $\mathrm{S}_{\mathrm{c} \text {-traffic, }}$ is determined by a modified Spangler stress equation and is given by

$$
S_{c-\text { traffic }}=\frac{6 k_{m} W_{\text {traffic }} E t r}{E t^{3}+24 k_{d} p r^{3}}
$$

where $\mathrm{L}_{\mathrm{e}}$ is the effective length of the pipe, $\mathrm{W}_{\text {traffic }}$ is the traffic load per unit length of the pipe and other parameters as defined earlier. The traffic load per unit length of pipe is developed using a numerical integration of the Boussinesq theory for a surface point load and is given by

$$
W_{\text {traffic }}=\frac{I_{c} C_{t} F}{L_{e}}
$$


where $I_{c}$ is the impact factor, $C_{t}$ is the surface load coefficient, and $F$ is the magnitude of surface wheel load. Based on a single AASHTO H-20 truck [11] on unpaved road, $F=16,000 \mathrm{lb}$ and $\mathrm{I}_{\mathrm{c}}=1.5$. An effective length of 3 feet is usually used in the field [12]. $\mathrm{C}_{\mathrm{t}}$ is computed using an equation listed in AWWA C150 [10] for pipe cover depths ranging from 2.5 feet to 32 feet.

$$
\begin{aligned}
C_{t}= & 1-\frac{2}{\pi} \arcsin \left[H \sqrt{\frac{A^{2}+H^{2}+1.5^{2}}{\left(A^{2}+H^{2}\right)\left(H^{2}+1.5^{2}\right)}}\right]+ \\
& \frac{2}{\pi}\left[\frac{1.5 A H}{\sqrt{A^{2}+H^{2}+1.5^{2}}}\right]\left[\frac{1}{A^{2}+H^{2}}+\frac{1}{H^{2}+1.5^{2}}\right]
\end{aligned}
$$

where $\mathrm{A}$ is the outside radius of pipe and $\mathrm{H}$ as defined earlier.

If the pipe material remains within the elastic range, the maximum circumferential stress, $\mathrm{S}_{\mathrm{c}}$, in the pipe can be obtained by adding the three components as follows

$$
S_{c}=S_{c-\text { fluid }}+S_{c-\text { soil }}+S_{c-\text { traffic }}
$$

\subsection{Longitudinal stresses}

External loads also cause the pipe to have bending stresses in the longitudinal direction. Longitudinal stresses are generally dependent on the pipe supports and loading along the length of the pipe. Long pipes can have longitudinal tensile stresses as a result of Poisson's ratio effect from the outward radial action of the internal fluid pressure. This longitudinal tensile stress due to the fluid in the pipe, $\mathrm{S}_{\text {l-fluid, }}$, can be determined from

$$
S_{l-\text { fluid }}=\frac{\mu p r}{t}
$$

where $\mu$ is the Poisson's ratio of the pipe material.

Another stress in the longitudinal direction is thermal stress, $\mathrm{S}_{1 \text {-thermal, which is }}$ caused by the differences in installation and operation temperatures. Thermal stress is determined by

$$
S_{\text {l-thermal }}=\alpha E \Delta \theta
$$

where $\alpha$ is the coefficient for thermal expansion and $\Delta \theta$ is the difference in installation and operation temperatures and $\mathrm{E}$ as defined earlier.

The last factor that contributes to the longitudinal stress is unevenness or settlement of the pipe bedding. This stress, $\mathrm{S}_{\text {1-bedding, }}$, is determined by

$$
S_{l-b e d d i n g}=\operatorname{Er} \chi
$$


where $\chi$ is the longitudinal curvature of the bend pipe and the other parameters as defined earlier. Summing up all three of the longitudinal stresses, the total maximum longitudinal stress, $\mathrm{S}_{1}$, is obtained by

$$
S_{l}=S_{l-\text { fluid }}+S_{l-\text { thermal }}+S_{l-\text { bedding }}
$$

\subsection{Stresses in rehabilitated pipes}

Corrosion can cause a loss in pipe wall thickness which in turn reduces the strength of the pipe. Internal corrosion depends on the internal fluid properties and their interaction with the pipe material, while external corrosion is dependent on the soil type, rate of oxygen depletion and replenishment, soil water movement, and presence of corrosion protection. The thickness, $t$, in the equations above includes estimated losses due to corrosion [9].

A pipe that has been rehabilitated using FRP liners will result in an increased pipe wall thickness. Therefore, a new, total wall thickness should be used in the stresses equations presented. Using the principle of transformed composite section, the total wall thickness, $t_{t}$, can be calculated from

$$
t_{t}=\left(t-t_{\text {loss }}\right)+\frac{E_{F R P} t_{F R P}}{E}
$$

where $t_{\text {loss }}$ is the loss in wall thickness due to corrosion, $E_{F R P}$ is the modulus of elasticity of the FRP liner, and $t_{\mathrm{FRP}}$ is the wall thickness of the FRP liner and other parameters as defined earlier.

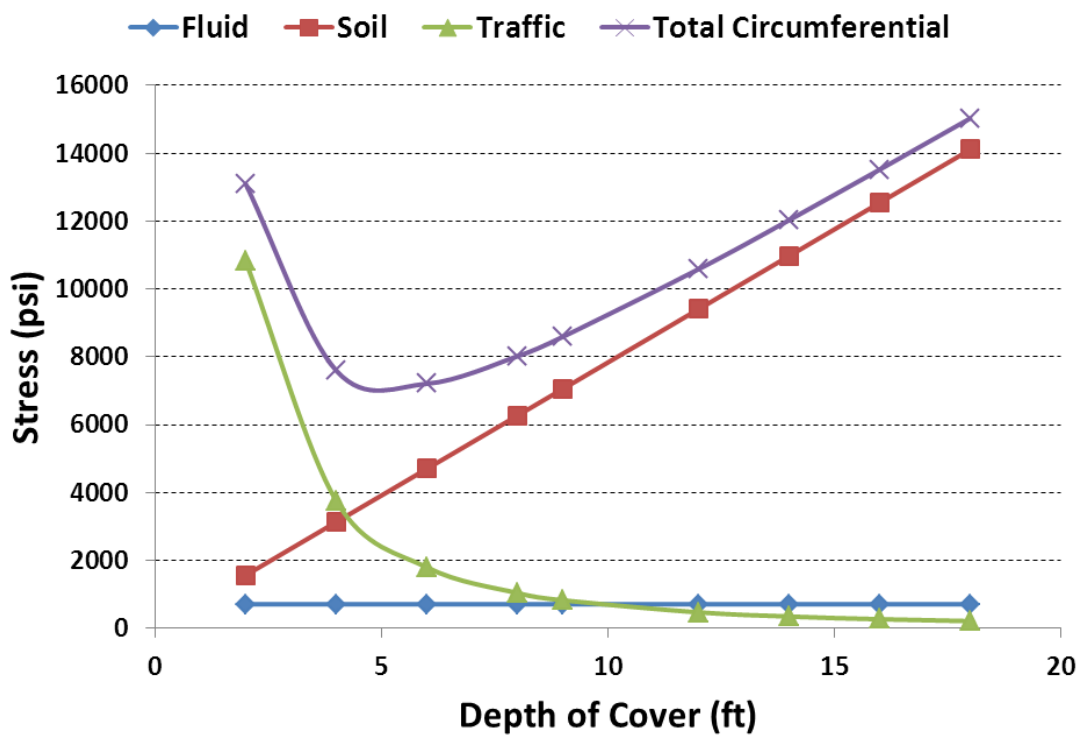

Figure 1: Relationship between internal fluid pressure and circumferential stresses. 
At this stage of the research, a computer program is written that incorporates all circumferential stress components. As an example, a numerical analysis of stress for ANSI 40 steel pipe with a diameter of 20 inches buried at a depth of 9 feet is shown in figure 1. The figure shows the relationship between the internal pressure in a pipe and circumferential stresses, and it shows that both the soil and traffic stresses decrease as the internal pressure increases. This is due to the pressure stiffness term in the Spangler stress equation used to calculate the stresses.

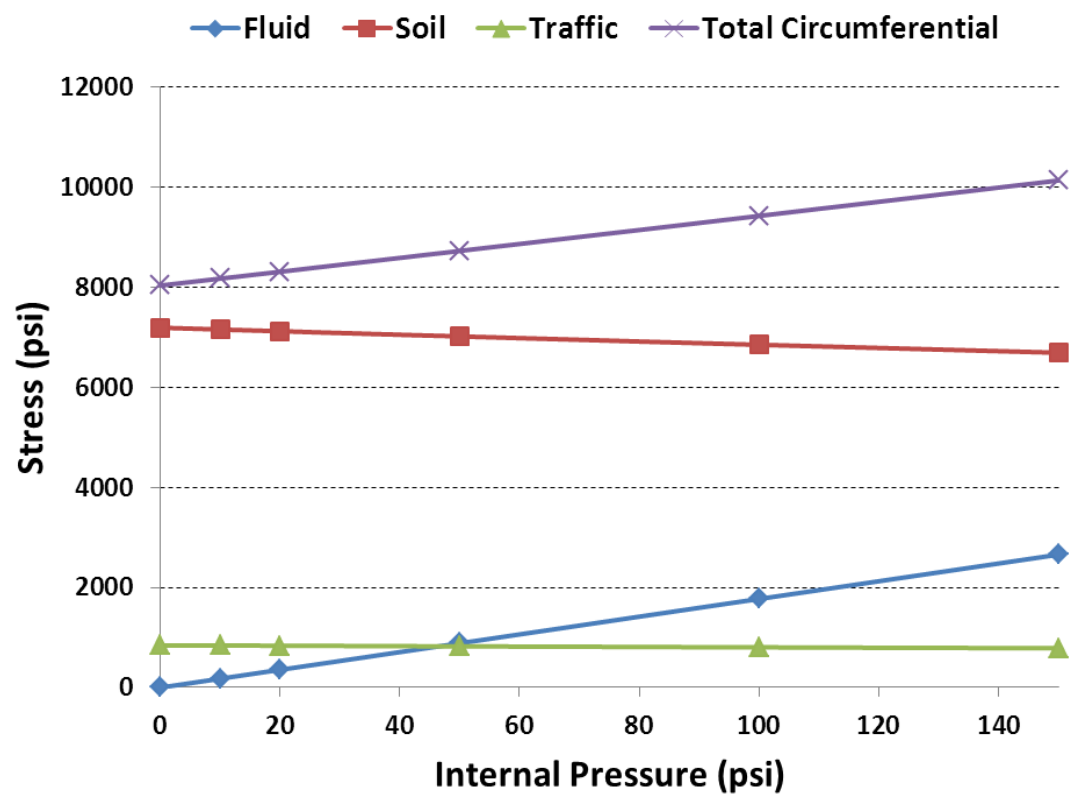

Figure 2: Relationship between the depth of cover over the pipe and stresses in the pipe wall.

Figure 2 shows the relationship between the depth of cover over the pipe and the stresses in the pipe wall. It shows that as the depth of cover increases, the traffic stress decreases dramatically. This is expected because there is more soil over the pipe to dissipate the traffic load. Note that there is an optimal depth of cover for the pipe where the total stress is minimal and as shown in the figure it is dependent on the diameter of the pipe. Figure 3 shows the difference between stresses in a regular steel pipe, a corroded steel pipe, a corroded steel pipe with $1 / 8$ inch of GFRP liner, and a corroded steel pipe with $1 / 8$ inch of CFRP liner. It is evident that the corroded steel pipe with $1 / 8$ inch of CFRP liner has the least amount of circumferential stress, hence making the pipe stronger.

\section{Conclusion}

This paper presents numerical analysis of stresses for pipes rehabilitated with cured-in-place-pipe (CIPP) linings. The analysis incorporates stress contributions 
due to fluid, soil and traffic loadings. Preliminary example outputs are provided for a given pipe using a program developed in support of this research. The results include stress reductions due to applied liner dimensions, relationship between the internal pressure in pipes and stresses in the pipe walls, and the interaction between optimal depth of cover and total circumferential stress. The reduction of stress values is presented due to CFRP and GFRP liners which are used as rehabilitation options. Current research is underway to expand the computer program to include longitudinal stresses computation for any type of liner. In addition, appropriate power laws are being investigated to model the effect of corrosion as accurately as possible. The research is also expanding to include the use of similar methods for concrete pipes.

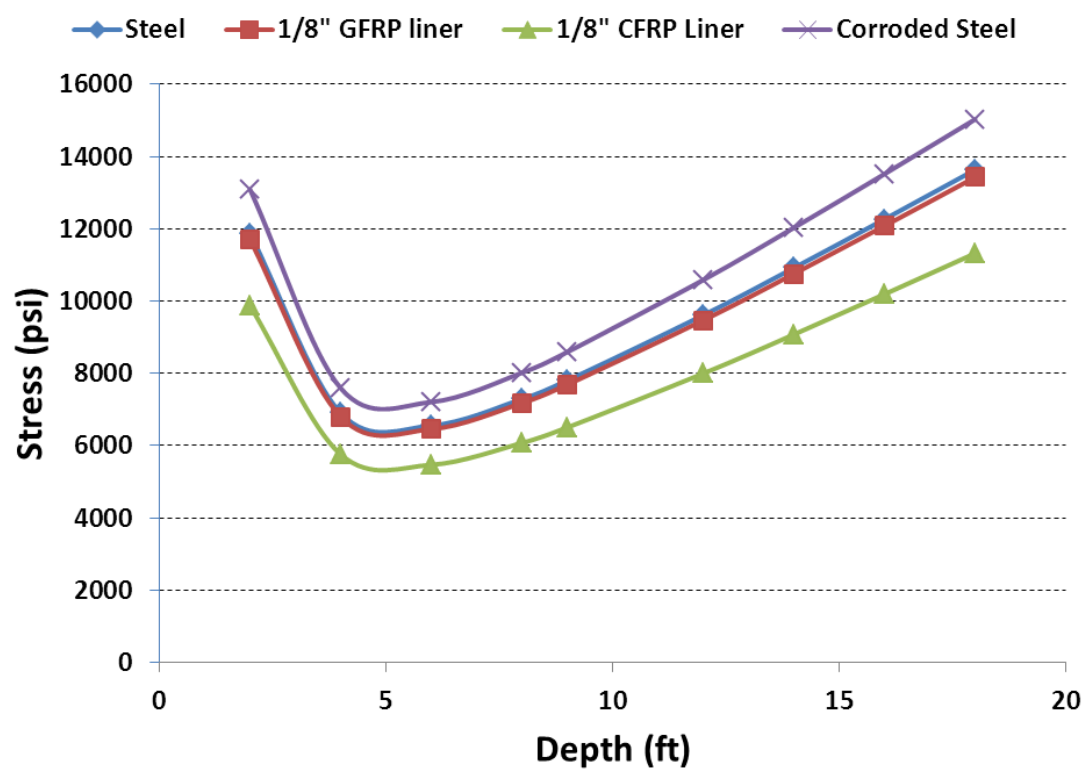

Figure 3: $\quad$ Stress reduction using liners.

\section{References}

[1] Selvakumar, A., Clark, R., \& Sivaganesan, M., Costs for water supply distribution system rehabilitation. Environmental Protection Agency. 2002.

[2] Sustainable Water Infrastructure. Environmental Protection Agency. http://water.epa.gov/infrastructure/sustain/index.cfm

[3] Wastewater Collection Systems. Environmental Protection Agency. http:/www.epa.gov/awi/wasterwater.html

[4] Sterling, R., Wang, L., \& Morrison, R., Rehabilitation of wastewater collection and water distribution systems. 2009. 
[5] Jaganathan, A., Allouche, E., \& Baumert, M., Experimental and numerical evaluation of the impact of folds on the pressure rating of CIPP liners. Tunnelling and Underground Space Technology, volume 22, issue 5-6, pp. 666-678, 2007.

[6] Lee, L.S., Estrada, H., \& Baumert, M., Time-dependent reliability analysis of FRP rehabilitated pipes. Journal of Composites for Construction, volume 14, number 13, pp. 272-279, 2010.

[7] Mifek, R., Rehabilitation of Sewerage System Structures, $9^{\text {th }}$ technical conference for doctoral study, JUNIORSTAV, pp. 231-232, 2007.

[8] Ahammed, M., \& Melchers, R.E., Probabilistic analysis of underground pipelines subject to combined stresses and corrosion. Journal of Engineering Structure, volume 19, issue 12, pp. 988-994, 1997.

[9] Spangler, M.G., \& Handy, R.L., Soil Engineering. 819 pages, Harper and Row, NY, 1982.

[10] American Water Works Association, Fiberglass Pipe Design. 178 pages, 2008.

[11] American Association of State Highway and Transportation Officials, AASHTO LRFD Bridge Design Specifications. 2007.

[12] Warman, D. J., Hart, J. D., \& Francini, R. B., Development of a Pipeline Surface Loading Screening Process \& Assessment of Surface Load Dispersing Methods. 2009. 